\title{
Determinants of Contraception Use among Female Adolescents in Bangladesh
}

\author{
Md. Musa Khan ${ }^{1}$, Mohammad Emdad Hossain ${ }^{1} \&$ Mohammad Nazmul Hoq ${ }^{1}$ \\ ${ }^{1}$ Department of Business Administration, International Islamic University Chittagong, Bangladesh \\ Correspondence: Mohammad Emdad Hossain, Department of Business Administration, International Islamic \\ University Chittagong, Road-03, House-27, Dhanmondi R/A, Dhaka 1205, Bangladesh. Tel: 880-15-5784-9422. \\ E-mail: mehapstat@gmail.com
}

Received: May 16, 2012 Accepted: July 3, 2012 Online Published: September 20, 2012

doi:10.5539/ass.v8n12p181 URL: http://dx.doi.org/10.5539/ass.v8n12p181

\begin{abstract}
The purpose of this study is to examine various socio-economic and demographic factors associated with contraception use among adolescents of Bangladesh. For this purpose, the present study utilizes the nationally representative survey data of Bangladesh Demographic and Health Survey, (National Institute of Population Research and Training (NIPORT), 2009). The cross-tabulation and Logistic regression analyses have been used to estimate the factors affected the use of contraception in Bangladesh. Respondents' education, their husbands' education, type of place of respondents, involvement with NGO program, marital duration, age at first marriage, age of respondent, communication between husband and wife, respondent currently working place, number of visits by family planning (FP) field workers and number of living children. Age at first marriage and age of respondents type of place of residence have been found to have significant effect on contraception use by both cross-tabulation and Logistic regression analyses. The study shows that adolescents who have at least one living child are tend to more use of contraceptive methods than those who have no living child.
\end{abstract}

Keywords: adolescence, contraception, contraceptive prevalence, family planning, Bangladesh

\section{Introduction}

The term adolescence is variously defined in study like this one as "the state or process of growing up," "the period of life from puberty to maturity" and "the period of transition from childhood to adulthood, [Encompassing] both the development to sexual maturity, and to psychological and relative economic independence" (United Nations, 1987). The age range implied by such description is obviously imprecise. Operational definitions vary. The United Nations (United Nations, 1987) chose to look at the reproductive behavior of teenagers; i.e., those in the age range 13-19, in its work on this subject. (Caroline \& Barney, 1993), the Population Reference Bureau in its use of Demographic and Health Surveys data (Yinger, Sherbinin, Ochoa, Morris, \& Hirsch, 1992), and the World Health Organization's (World Health Organization (WHO), 1975) work, The Health of Youth, focus on the age range 15 to 19. Studies of "youth" tend to address a broader and somewhat older age group-young people ages 15 to 24 . Throughout this study, the term "adolescent" refers to women ages 15 to 19. Statements about "teenagers" and "teenage" behavior refer to the broader age range 13-19 (as an approximation of the post-puberty population under age 20), but as a practical matter most teenage reproductive behavior tends to occur in the age range 15 to 19 in most populations.

Adolescents constitute one-fourth of the total population (133 million) of Bangladesh. The overall adult literacy rate is 41 percent. For secondary school the net enrollment ratio of girls is 51 percent while it is 49 percent for boys (Bangladesh Bureau of Statistics, 2012). Early marriage, especially among females, is highly prevalent in Bangladesh. There are more than 2.5 million married adolescents in Bangladesh (National Institute of Population Research and Trainging (NIPORT), 2003). Seventy eight percent of adolescent girls marry before reaching age 18 (National Institute of Population Research and Training (NIPORT), 2001). Adolescent fertility is 144 births per 1000 women below age 20 and one-fifth of adolescent mothers have little knowledge about life-threatening conditions during pregnancy; 60 percent receive no antenatal care (National Institute of Population Research and Trainging (NIPORT), 2003). Ninety-two percent of mothers aged less than 20 years deliver at home and the unmet need for contraception among this group is 27 percent (National Institute of Population Research and Trainging (NIPORT), 2003). A large majority of adolescents (both married and unmarried) do not have 
information on sexuality, contraception, or STDs and HIV/AIDS (Barkat, Khan, Majid, \& Sabina, 2000). Nevertheless, RH education has not been a part of the education curriculum, and the existing service delivery system is not catering to the needs of unmarried adolescents. Rapid population growth has been perceived as a great threat to the development of Bangladesh with its limited resources. The scarcity of resources and subsistence level economic conditions characterize the Bangladesh economy (Khuda e. a., 1991). Bangladesh is predominantly dependent on land, with agriculture as its primary industry; however, increasing population pressure on the land is continually decreasing the land-man ratio resulting the increasing rate of land less people.

There are many factors that determine population growth. Before policy formation, it is essential to identify the important determinants. Among the factors that change population growth, the effect of migration is negligible in Bangladesh. Mortality is not merely a biological phenomenon but depends on the medical technology and in the advancement of health and medical infrastructure, the nutritional stands and several social factors like working conditions, education, social security schemes, and status of women, housing condition and several other cultural practices. Because of the advancement of medical science and technology the death rate is comparatively prevailing at a low level in Bangladesh. Family planning campaign begun in Bangladesh in early fifties under voluntary auspices of a group of social workers. The 1976 Bangladesh Fertility Survey (BFS) data show that only 7 percent of eligible couples were using contraceptives. Although the currently contraceptive use rate increased to 56 percent in 2004 from 7 percent in 1975, the demographic impact of higher contraceptive use remains unclear in Bangladesh. Nonetheless, the contraception use rate is lower among adolescents married females due to ignorance, illiteracy, fear, religious sentiment and some other factors, contraceptive use rate is still lower than the target rate. Knowledge of implants has increased from 56 percent of currently married women in 1999-2000 to 82 percent in 2007. Therefore, the main objective of this study is to examine the levels as well as the differentials in contraceptive use among adolescents in Bangladesh.

\section{Literature Review}

Bangladesh is the $9^{\text {th }}$ most populous country in the world with a total population of 142.319 million (Bangladesh Bureau of Statistics, 2012). Early marriage and early birth are common phenomena in our society resulting higher fertility rate. Despite the low socio-economic indicators, Bangladesh is the best example of a country with strong family planning program effort, which has brought about significance decline in fertility. The total fertility rate (TFR) has declined from 7 births per women in the 1970 to 2.7 in 2007 (National Institute of Population Research and Training (NIPORT), 2009), which is still quite high compared to its area and resources. This high fertility is characterized by low age at marriage and low contraceptive use rate, mostly among adolescents. Most adolescent girls being illiterate are not aware of family planning methods, and even if they are, they do not have easy access to family planning services or fail to utilize them due to inhibitions or pressure to attain motherhood soon after marriage to satisfy their families. This particular behavior increases the chance of unplanned pregnancies among adolescents. Overall, one-third of births in Bangladesh can be considered as unplanned; 19 percent were mistimed and 14 percent were unwanted. Using World Fertility Survey Data, (Bongaarts, 1990) estimated that about 24 percent of all births in Bangladesh during 1975 were unwanted.

Considering the adolescents as the distinct potential fertility cohort and which is again largely responsible for early age at first marriage, therefore, the specific objective of this study is to examine the marriage pattern of adolescent women and contraceptive use by some socio-economic and behavioral characteristics of adolescent women in Bangladesh. The study also reveals the effect of female adolescent age at marriage and contraception behavior and also draws out important policy implications from the findings. (Chowdhury, 1977) has found that education is inversely related to fertility and also positively related to practice of contraception for Bangladesh. Female education is found to have relatively more effect on fertility and practice on the practice of contraception than husband's education. Malnutrition, which affects biological mechanism of human body, is likely to be directly related to the fertility performance.

(Chaudhury, 1984) has studied the Bangladesh Fertility Survey (BFS) of 1975 to examine the relationship between three aspects of female status (education, work experience and age at first marriage) and the use of contraception and fertility of Bangladesh. Education is found to be the variable most strongly correlated with use of contraception and is also one of the significant variables explaining fertility behavior. The most important factor explaining fertility behavior is age at first marriage. The higher the ages at marriage, the lower the fertility, when all other factors are held constant. Work experience has very little or no effect on current use of contraception and fertility. Using a logit linear model (Tuladhar, 1985) has shown that the prevalence of current contraception is directly related to number and sex to living children and the age of the women. The prevalence rates are higher among the women who did not want more children and women who had discussed family size with husbands. The prevalence varies according to women education and work status. Women who have access 
to the family planning service within a short distance have higher prevalence than those who do not.

(Ahmed, 1987) has examined the determinants of contraceptive use in rural Bangladesh. An unusual feature of this study is the contraceptive use is viewed as determined by two policy-related variables: motivation for fertility regulation and costs of regulation. Motivation for fertility regulation is theoretically the difference between potential family size and desired family size. Motivation can be increased either by increasing natural fertility of the child survival rate, or both, or by decreasing the demand for children. It can be expected that with modernization the potential family size will increase whereas the demand for children will decrease. His finding suggested that to reduce costs and increase use rates, the distance to family planning clinics must be decreased. Fitting a logistic regression model to the Matlab Family planning Health Services Project (FPHSP) data. (Chowdhury \& Phillips, 1989) have shown that age and number of living children are highly correlated with current contraceptive use. The negative effect of age reflects the fact that young women are more likely to use contraceptive once the number of living children is allowed for. A higher number of living children at a younger age apparently motivate couple to accept, while older women with the same number of living children do so less frequently.

Due to early marriage, low contraceptive use, and the social expectation to have children soon after marriage, childbearing begins early in Bangladesh. Although the average age at marriage for females has been rising intermittently since the 1960s the median age at which Bangladeshi women marry is low compared to other developing countries. There has also been a substantial decrease in the total fertility rate in the last four decades, but most of the decrease was observed among the older cohorts (age 25 and above), not the younger group, and without any substantial increase in the age of first birth. The review of literature of use of contraception shows that a number of variables are affecting on contraception use. However, the predictors are changing through time since the facilities and awareness are changing day by day. Hence, it is necessary to identify the segment of population where programs need strengthen in order to achieve the goal for control of population

\section{Objective of the Study}

In this study, an attempt has been made to examine the predictors of contraception use in Bangladesh. There are many factors that influence the use of contraception. Thus, greater attentions have to be paid to find out the factors that are influencing use of contraceptive methods and ultimately the growth of population. However, the specific objectives of this research are:

1) To find the percentage of ever and current use of contraception by various socio-economic variables.

2) To determine whether ever and current use of contraceptives vary among adolescent women of Bangladesh by selected socio-economic and demographic characteristics.

3) To examine the effects of available socio-demographic factors on both ever use and current use of contraception.

\section{Materials and Methods}

This study uses data extracted from the 2007 Bangladesh Demographic and Health Survey (National Institute of Population Research and Training (NIPORT), 2009), which conducted during the period from 24 March to 11 August 2007, on behalf of the Government of Bangladesh by National Institute for Population Research and Training (NIPORT), with funding from the United States Agency for International Development (USAID)/Dhaka. The description of the survey can be found elsewhere. The sampling frame for the survey considered all households in Bangladesh from which a nationally representative sample of 10,819 households was selected; 10,461 were occupied. Of the households occupied, 10,400 (99.4\%) were successfully interviewed. In these households, a total of 11,178 ever-married females aged less than 50 years were identified as eligible for individual interview. Of them, 10996 females (or 98.4\%) were successfully interviewed. Among the 10996 ever-married females, the numbers of urban and rural respondents are $4151(37.75 \%)$ and $6845(62.25 \%)$, respectively. The sample had been taken 5 years prior to (National Institute of Population Research and Training (NIPORT), 2009) survey. Out of 10996 ever-married females, 1348 (12.26\%) are found to age under age 20, known as adolescents. The associations between contraception use and selected explanatory variables have been tested by applying cross-tabulation analysis. The cross-tabulation analysis is an important in first step for studying the relationship between uses of contraception with several characteristics. However, such analysis fails to address use of contraception predictors completely because of ignoring other covariates. Hence, Logistic regression analysis has also been adopted in order to estimate independent effects of each variable while controlled for others. This analysis has considered all the covariates that have found significant in cross-tabulation analysis. 


\subsection{Variables}

Respondent's Education, Religion, Type of place of residence, Access to mass media, Husband's occupation, Husband's education, Respondent currently working, Marital duration, Age at first marriage, Involvement with NGO program, Communication between husband and wife, Desire for more child, Number of visits by FP field worker, Number of living children, Age of respondents.

\subsection{Ever and Current Use of Contraception}

The term 'ever use' refers to the use of contraceptive method (Pill, IUD, Injections, Condom, Female Sterilization, Male Sterilization, Periodic Abstinence, Norplant etc.) at any time before the date of interview without making any distinction between past use and current use. Any respondent reporting that she or her spouse had ever used some form of contraception was counted as an ever user regardless of the time of use. Also, an ever user might have used more than one method.

The term 'current use' refers to the method that was being used of an individual client at the time of the survey. Thus, any respondent (or, her spouse) using a family planning method at the time of survey was regarded as a current user.

\section{Results}

Table 1. Percentage, cross tabulation and associated summary statistics of adolescent respondent who have ever used and are currently using at least one contraceptive method by different characteristics

\begin{tabular}{|c|c|c|c|c|c|c|}
\hline \multirow{2}{*}{$\begin{array}{l}\text { Background } \\
\text { Characteristics }\end{array}$} & \multicolumn{3}{|l|}{ Ever use } & \multicolumn{3}{|l|}{ Current use } \\
\hline & Percentage & $\begin{array}{l}\text { Chi-square } \\
\text { value }\end{array}$ & $\begin{array}{l}\text { Significance } \\
\text { level }\end{array}$ & Percentage & $\begin{array}{l}\text { Chi-square } \\
\text { value }\end{array}$ & $\begin{array}{l}\text { Signif } \\
\text { level }\end{array}$ \\
\hline \multicolumn{7}{|c|}{ Respondent's Education } \\
\hline Illiterate & $45.4(74)$ & & & $27.6(45)$ & & \\
\hline Primary literate & $58.6(214)$ & 61.967 & 0.000 & $34.0(124)$ & 20.975 & 0.000 \\
\hline $\begin{array}{l}\text { Secondary and } \\
\text { Higher }\end{array}$ & $73.8(605)$ & & & $43.9(360)$ & & \\
\hline \multicolumn{7}{|l|}{ Religion } \\
\hline Muslim & $66.7(835)$ & 1.946 & 0.163 & $39.6(495)$ & 0.770 & 0.380 \\
\hline Non-Muslim & $59.8(58)$ & & & $35.1(34)$ & & \\
\hline \multicolumn{7}{|c|}{ Type of place of residence } \\
\hline Rural & $63.3(594)$ & 11.760 & 0.001 & $37.7(354)$ & 2.924 & 0.087 \\
\hline Urban & $72.9(299)$ & & & $42.7(175)$ & & \\
\hline \multicolumn{7}{|c|}{ Access to mass media } \\
\hline No access & $57.4(224)$ & 19.050 & 0.000 & $36.2(141)$ & 2.197 & 0.138 \\
\hline Have access & $69.8(669)$ & & & $40.5(388)$ & & \\
\hline \multicolumn{7}{|c|}{ Husband's occupation } \\
\hline Agriculture & $64.1(195)$ & & & $43.1(131)$ & & \\
\hline Service & $73.3(107)$ & 5.817 & 0.121 & $43.2(63)$ & 7.297 & 0.063 \\
\hline Business & $69.0(198)$ & & & $41.5(119)$ & & \\
\hline Others & $64.3(393)$ & & & $35.4(216)$ & & \\
\hline \multicolumn{7}{|c|}{ Husband's education } \\
\hline Illiterate & $52.3(184)$ & & & $30.1(106)$ & & \\
\hline Primary & $68.6(299)$ & 43.958 & 0.000 & $41.3(180)$ & 17.111 & 0.000 \\
\hline $\begin{array}{l}\text { Secondary } \\
\text { Higher }\end{array}$ & $73.2(410)$ & & & $43.4(243)$ & & \\
\hline \multicolumn{7}{|c|}{ Respondent currently working } \\
\hline No & $64.6(727)$ & 8.645 & 0.003 & $37.8(426)$ & 5.073 & 0.017 \\
\hline Yes & $74.8(166)$ & & & $46.4(105)$ & & \\
\hline
\end{tabular}




\section{Marital duration}

$0-2$ years

$58.7(477)$

$\begin{array}{ll}76.7(372) & 52.296 \\ 86.3(44) & \end{array}$

$31.0(252)$

3-5 years

0.000

$50.9(247)$

58.921

0.000

6 and over

$70.5(606)$

19.588

0.000

$58.8(30)$

Age at first marriage

$\begin{array}{lcc}\leq 15 \text { years } & 70.5(606) & 19.588 \\ >15 \text { years } & 58.7(287) & \\ \text { Involvement with NGO program } & \\ \text { No } & 63.4(638) & 14.170 \\ \text { Yes } & 74.5(255) & \end{array}$

Communication between husband and wife

Never

$51.4(360)$

Once or twice

80.4(394)

146.045

0.000

More often

$88.0(139)$

0.000

$43.7(375)$

19.333

0.000

$31.5(154)$

Desire for more child

No more, none

$72.5(158) \quad 4.515$

0.034

36.2(364)

15.576

0.000

48.2(165)

Have another child

65.0(735)

15.1(106)

63.5(311)

357.491

0.000

$70.9(112)$

Number of visits by FP field worker

No visit

63.6(741)

28.132

1-2 visits

84.2(101)

28.132

82.3(51)

0.000

35.2(411)

3 or more visits

children

Number of living children

No child

$53.0(330)$

91.315

0.000

$34.4(75)$

2.555

0.110

Have child

$77.7(563)$

Age of respondents

\begin{tabular}{llll}
$\leq 16$ years & $57.9(187)$ & & \\
$17-18$ years & $65.4(423)$ & 22.858 & 0.000 \\
$>18$ years & $74.9(283)$ & & \\
Total & $\mathbf{6 6 . 0 2 ( 8 9 3 )}$ & & \\
\hline
\end{tabular}

40.2(454)

$\begin{array}{lll}65.8(79) & 57.944 & 0.000\end{array}$

62.9(39)

21.5(134)

152.798

0.000

54.5(395)

33.4(108)

$37.9(245) \quad 13.571 \quad 0.001$

Table 2. Logistic regression estimates of ever use of any contraceptive methods by some selected socio-economic and demographic characteristics

\begin{tabular}{|c|c|c|c|c|c|c|}
\hline \multirow{2}{*}{$\begin{array}{l}\text { Background } \\
\text { Characteristics }\end{array}$} & \multicolumn{3}{|c|}{ Ever use of contraceptive method } & \multicolumn{3}{|c|}{ Current use of contraceptive method } \\
\hline & $\begin{array}{l}\text { Logistic } \\
\text { regression } \\
\text { co-efficient }(\beta)\end{array}$ & S.E & $\begin{array}{l}\text { Odds ratio } \\
{[\operatorname{Exp}(\beta)]}\end{array}$ & $\begin{array}{l}\text { Logistic } \\
\text { regression } \\
\text { co-efficient }(\beta)\end{array}$ & S.E & $\begin{array}{l}\text { Odds ratio } \\
{[\operatorname{Exp}(\beta)]}\end{array}$ \\
\hline \multicolumn{7}{|c|}{ Respondent's Education } \\
\hline Illiterate (RC) & - & - & - & - & - & - \\
\hline Primary literate & 0.512 & 0.223 & $1.668 * *$ & 0.168 & 0.263 & 1.183 \\
\hline $\begin{array}{l}\text { Secondary and } \\
\text { Higher }\end{array}$ & 1.215 & 0.224 & $3.372 * * *$ & 0.602 & 0.254 & $1.826^{* *}$ \\
\hline \multicolumn{7}{|c|}{ Type of place of residence } \\
\hline Rural (RC) & - & - & - & - & - & - \\
\hline Urban & 0.401 & 0.154 & $1.493 * *$ & 0.197 & 0.162 & 1.217 \\
\hline \multicolumn{7}{|c|}{ Access to mass media } \\
\hline No access (RC) & - & - & - & \multirow{2}{*}{\multicolumn{3}{|c|}{ Insignificant in cross-tabulation. }} \\
\hline Have access & 0.171 & 0.156 & 1.186 & & & \\
\hline
\end{tabular}




\section{Respondent currently working}

No(RC)

Yes 0.368

0.197

$1.445^{*}$

0.199

0.201

1.220

\section{Husband's occupation}

Agriculture (RC) Insignificant in cross-tabulation.

Service

$-0.290$

0.226

0.749

Business

$-0.111$

$0.271 \quad 0.895$

Others

$-0.535$

$0.190 \quad 0.586^{* * *}$

Husband's education

Illiterate (RC)

Primary literate $\quad 0.553$

Secondary and 0.720

Higher

$0.1791 .738^{* * *}$

0.263

0.201

1.300

$0.1902 .054^{* * *}$

0.471

0.212

$1.601 * *$

\section{Marital duration}

$0-2$ years (RC)

3-5 years

0.443

$0.2121 .558^{* *}$

0.567

0.219

$1.763 * *$

6 and over

0.916

$0.524 \quad 2.499 *$

0.621

0.453

1.861

Age at first marriage

$\leq 15(\mathrm{RC})$

$>15 \quad-0.554$

$0.2070 .575^{* * *}$

$-0.011$

$0.222 \quad 0.989$

Involvement with NGO program

No (RC)

Yes

0.307

$0.167 \quad 1.359 *$

0.391

$0.1731 .478^{* *}$

Communication between husband and wife

Never (RC)

Once or twice

1.179

$0.152 \quad 3.251^{* * *}$

2.250

$0.1589 .485^{* * *}$

More often

1.931

$0.2776 .895^{* * *}$

2.854

0.235

$17.350^{* * *}$

Number of visits by FP field worker

No visit (RC)

1-2 visits

0.742

$0.2912 .100^{* *}$

0.903

$0.2542 .467 * * *$

3 or more visits

0.285

$0.389 \quad 1.330$

0.489

$0.342 \quad 1.630$

Number of living children

No child (RC)

Have child 0.836

$0.1592 .306^{* * *}$

1.408

$0.1774 .089^{* * *}$

Age of respondents

$$
\leq 16 \text { years }(\mathrm{RC})
$$

17-18 years

0.234

$>18$ years

0.513

$\begin{array}{ll}- & - \\ 0.204 & 1.264 \\ 0.259 & 1.670^{* *}\end{array}$

$-0.280$

0.219

0.775

$-0.125$

0.271

0.882

\section{Desire for more child}

No more, none

Insignificant in cross-tabulation (RC)

Have another child

$-0.25$

$0.195 \quad 0.778$

Constant

$-2.016$

$0.3150 .133^{* * *}$

$-3.314$

0.328

$0.036 * * *$

Note: "RC" Signifies reference category. ${ }^{*} \mathrm{p}<0.10,{ }^{* *} \mathrm{p}<0.05,{ }^{* * *} \mathrm{p}<0.01$ 


\section{Discussion}

\subsection{Cross Tabulation}

The distribution of contraception use by socio-economic, bio-demographic and family planning variables is shown in Table1 \& Table2. Table1 provides contraceptive prevalence rates by level of education. Both ever use and current contraceptive uses are increasing with the increase of respondents' education. Table1 shows that 73.8 percent respondents are ever user who have secondary and higher education as compared to 45.4 percent illiterate respondents. Similar pattern happened in case of current user i.e. 43.9 percent respondents have secondary and higher education whereas illiterate respondents are 27.6 percent. The chi-square test at 0.1 percent level of significance shows that that there is a strong significant association between practice of contraception and respondents level of education. In Table -1, contraception use has been examined according to religion (Muslim and Non-Muslim). Table shows that about 66.7 and 59.8 percent of the Muslim and Non-Muslim respondents respectively have ever used at least one contraceptive. Furthermore, Table shows that about 39.6 and 35.1 percent Muslim and Non-Muslim respondents respectively are currently using contraceptive.

Rural Bangladesh is lagging behind modern facilities. The relatively higher economic cost of bearing children and the lower economic value of children in urban areas, opportunity cost for mother's time might have played an important role in lowering the fertility of urban women through the practice of effective methods of birth control. Chi-square test shows that both ever and current use of contraception is an association between practice of contraception and place of residence. Practice of contraception by access to media has also been examined. Both ever (57.4\%) and current use (36.2\%) rate are lower for the adolescent women who have no exposure to modern mass media. To test the association between practice of contraception and connection with mass media by Chi-square test, it is seen that there is a positive association between ever use and mass media exposure.

From the Table1 we can expatiate on the occupation of husbands determining the use of contraception. Ever use of contraception of adolescent women whose husbands' occupation is service (73.3\%) practice more contraception method than those husbands' occupations are agriculture (64.1\%), business $(69.0 \%)$ and others (64.3\%). Similar pattern is followed by current use of contraception. In case of husbands' education, the ever and current rate of contraception use increases with increase of their level of education. As for example, at "no education" level, the ever and current use rates by husbands are 52.3 and 30.1 percent whereas it has been 73.2 and 43.4 percent in secondary and higher education level respectively. Chi-square test at 0.1 percent level of significance shows that there is a strongly positive association between husband's education and practice of contraceptive.

It is noticed from the table that the ever and current use of contraception among the respondents who are currently working are 74.8 and 46.4 percent respectively, whereas the respondents who are not working are 64.6 and 37.8 percent respectively i.e. currently working adolescent women practice contraception more than those who are not working. Chi-square test at 0.1 percent level of significance shows that there is a strongly positive association between working status of respondent's and practice of contraceptive. Contraceptive use is positively related to the duration of married life. In case of ever use of contraceptives, the Contraceptive Prevalence Rate (CPR) is found 86.3 percent when the duration of married life is more than 5 years, compared to 76.7 percent when the duration is $3-5$ years and 58.7 percent when duration of married life is less than 3 years. It is also observed that 50.9 percent currently use contraceptive when marital duration is 3-5 years as compared to 58.8 percent when marital duration is over 5 years and 31.0 percent when marital duration is less than 3 years. The chi-square value at 0.1 percent level of significance shows that there is a positive correlation between marital duration and use of contraception.

Age at first marriage, the adolescent women whose age is less than or equal to 15 years practice contraceptive method more times than the adolescent women whose age above 15 years. This indicates the women practice contraceptive method from their starting of marital life. The chi-square value at 0.1 percent level of significance shows that there is a strong positive correlation between age at first marriage and use of contraception. A close examination of Table -1 reveals that in case of both ever and currently using credit clients showed better performance to use contraceptive than non-credit clients do. Participation of women in credit activities increases their position in the family and they can participate as household decision makers. The chi-square value at 0.1 percent level of significance shows that there is a strong positive correlation between involvement with NGO program and use of contraception.

Table-1 reveals that, in the category of "Never communication" and "more often communication" there is a gulf difference of contraceptive taking. The couples in the former category take 51.4 percent (at ever use) whereas those in the latter category takes 88.0 percent (at ever use). Similarly for currently user the respondents those 
have "Never communication" with husband takes contraceptive method 15.1 percent; whereas the respondents those have "more often communication" takes 70.9 percent. The chi-square value at 0.1 percent level of significance shows that there is a strong positive correlation between "communication between husband and wife" and "use of contraception". It is observed from the table that ever user respondents who have no desire for more children are more time use contraceptive methods than those who have need another child. But in case of current user we get opposite result.

Practice of contraception by the number of visits of Family planning worker has been examined from the Table-1. It is clearly noticed that the more the number of visits of Family planning worker happen to respondents, the more they responds favorably to their use of contraception. Within the category of "No visits" it is explored that the ever and current use-rates of contraceptive taking are respectively 63.6 percent and 35.2 percent. In the case of 1-2 visits and 3 or more visits to the respondents we find that an increased number of respondents using contraceptive methods. The chi-square value at 0.1 percent level of significance shows that there is a strong positive correlation between Number of visits by FP field worker and use of contraception. From table it is seen that 53.0 and 21.5 percent childless respondents are ever and current contraceptive uses respectively while 77.7 and 54.5 percent respondents are ever and current use of contraceptive method who have child.

Both ever and current use of contraceptive has been rising with the increasing level of age of women. From the Table-1, it is seen that 57.9 and 33.4 percent of adolescent respondents whose age is below or at 16 years, are ever and currently use of contraceptive method respectively while 65.46 and 37.9 percent whose age ranges between 17-18 years are ever and currently use contraceptive method. On the other hand, 74.9 and 46.6 percent whose age is over 18 years are ever use and currently use of contraceptive method respectively. The chi-square value at 0.1 percent level of significance shows that there is a strong positive correlation between age of respondents and use of contraception.

\subsection{Logistic Regression}

Here we consider the variables which are significant in cross tabulation up to $10 \%$ significance level. Respondents' education is found to have a strong significant effect on the ever use and current use of contraception. The positive sign of the regression coefficient indicates that adolescent respondents, who are educated, are more likely to use contraceptives than those of illiterate respondents. The odds ratio of ever user for Primary literate and higher educated respondents are 1.668 and 3.372 respectively imply that they are 1.668 and 3.372 times more likely respectively to be ever users of contraceptives than the respondents who are illiterate. Similarly the odds ratio of current user is 1.826 for the respondents who have secondary and higher degree which implies that they are 1.826 times more likely to be current users of contraceptives than the respondents who are illiterate. Type of place of residence is observed to have a significant effect on the ever use of contraception. The positive sign of the regression coefficient indicates that urban respondents are more likely to be used contraceptives than rural respondents. The odds ratio for urban respondents is 1.493; imply that they are 1.493 times more likely to be ever uses of contraceptives than the respondents who are residing in rural areas.

Respondents' who are currently working have significant effect on ever use of contraception. The odds ratio for currently working respondent is 1.445 which indicates that they are 1.445 times more ever uses contraception than who are not working. Husband's occupations have significant effect on the current use of contraception. The odds ratio is 0.586 for the respondents whose husbands are in others category imply they are 0.414 times less likely to be current uses of contraceptives than their contemporaries whose husbands are in agriculture occupation. Similarly Husband's education has strong significant effect on the ever use and current use of contraception. The positive signs of the regression coefficient imply that respondents having educated husbands are more likely users of contraceptives than those of respondent's husband who belong to the "illiterate" category. The odds ratios for the respondents whose husbands have primary and higher education are 1.738 and 2.054, imply that they are 1.738 and 2.054 times more likely to be ever users of contraceptives than the respondents having husband belonging to the illiterate category. Similar pattern happened for the respondents whose marital duration over 2 years with compare to them whom duration less than 2 years.

Age at first marriage have a significant effect on the ever use and current use of contraception. The odds ratio for the respondents having marriage after 15 years is 0.575 imply that they are 0.425 times less likely to be ever users of contraceptives than the respondents having marriage occurred before or at 15 years. Respondents who are involved with NGO program have a significant effect on the ever use of contraception and also on current use of contraception. The positive signs of the regression coefficient imply that respondent's involvements with NGO are more likely to be ever users of contraceptives than those of respondents who are not involvement with NGO program. The odds ratios for ever and current user having involvement with NGO 
program are 1.359 and 1.478 respectively, which imply that they are 1.359 and 1.478 times more likely to be ever and current users of contraceptives than the respondents who have no involvement with NGO program.

Communication between husband and wife has a strong significant effect on the ever use of contraception and on current use of contraception. In ever user, the odds ratios for the respondents who have "once or twice" and "More often" communication with their husbands are 3.251 and 6.895 respectively which imply that they are 3.251 and 6.895 times more likely to be ever users of contraceptives than the respondents who have no communication with their husbands. Similarly, for current user the odds ratios for the respondents who have "once or twice" and "More often" communication with their husbands are 9.485 and 17.350 respectively which imply that they are 9.485 and 17.350 times more likely to be current use of contraceptives than the respondents who have no communication with their husbands.

Number of visits by FP field worker have a significant effect on the ever and current use of contraception. The odds ratio for the respondents who are visited "once or two times" by FP field worker is 2.10 , which imply that they are 2.10 times more likely to be ever users of contraceptives than the respondents who have not visited by FP field worker. Similarly for current user odds ratio for the respondents who are visited "once or two times" by FP field worker is 2.467 , which imply that they are 2.467 times more likely to be current use of contraceptives than the respondents who have not visited by FP field worker. Number of living children of respondents has a strong significant effect on the ever and current use of contraception. The positive signs of the regression coefficient imply that respondents who have children are more likely to be ever and current users of contraceptives than those of respondents who have no children. The odds ratios for ever and current users, having children are 2.306 and 4.089 respectively, imply that they are 2.306 times and 4.089 times more likely to be ever and current users of contraceptives than the respondents who have no children. Age of respondents has a significant effect on the ever use of contraception. The odds ratio for the respondents age over 18 years is 1.670 , implying that they are 1.670 times more likely to be ever use of contraceptives than the respondent whose age below and at 16 years.

\section{Conclusion and Recommendations}

This study investigates the predictors of contraception use in Bangladesh among female adolescents. It has utilized the national representative data from the Bangladesh Demographic and Health Survey (BDHS -2007). Both cross-tabulation and Logistic regression analysis techniques have been applied to identify the important predictors of contraception use. Since contraception is one of the important proximate determinants of fertility, the present study also analyzed the use of contraception by teenage females. In addition to the level of contraceptive use, multivariate Logistic Regression has also been employed to identify the rich factors of contraception. Contraception use accordance with background characteristics of the respondents illustrate that ever uses of contraception is extremely low among the illiterate respondents, among the respondents who have never communication with their husbands regarding family planning, among the respondents who have no children. On the hand, ever use of contraception is higher among the respondents whose age is over 18 years, among the respondents whose marriage occurred before 15 years, among the respondents and their husbands who have secondary education level, among the respondents whose marital duration is 6 years and over, among the respondents who have more communication with their husbands, who have more children and who have visited 1 or more times by Family Planning field workers. But the current use rates have depressive results. Bivariate analysis suggests that type of place of residence, respondent's educations, husbands educations, marital duration, respondent currently working status, involvement N.G.O program, communication between husband and wife, number of visits by FP field worker, number of living children and age of respondents have significant effects on both ever use and current use of contraception.

In view of findings of multivariate logistic analysis, it is evident that the explanatory variables such as respondents education, husbands education, marital duration, involvement with NGO program, communication between husband and wife, number of visits by FP field worker, number of living children are important in explaining both ever use and current use of contraception. Therefore, we recommend sustained efforts to raise awareness and motivation for proper contraceptive use. This can be brought about by facilitating access to more information, education of both husband and wife, NGO programs, effective communication by family planning workers, encourage to practice of contraception and communication with the couples in reproductive age.

\section{References}

Ahmed, B. (1987). Determinants of contraceptive use in rural Bangladesh: The demand for children, supply of children and costs of fertility regulation. Demography, 24(3), 361-373. http://dx.doi.org/10.2307/2061303

Bangladesh Bureau of Statistics. (2003). Bangladesh Population Census Report 2001, Preliminary Report. 
Dhaka, Bangladesh: Statistics Division, Ministry of Planning.

Bangladesh Bureau of Statistics. (2012). Bangladesh Population Census Report 2011, Summary Report. Dhaka, Bangladesh: Statistics Division, Ministry of Planning.

Barkat, A. S., Howlader, B., Khuda, J., Ross, A., \& Bose, H. L. (1996). Family planning unmet need in Bangladesh: Shaping of a Client-oriented Strategy. Dhaka university Research Corporation.

Barkat, A., Khan, S. H., Majid, M., \& Sabina, N. (2000). Adolescent sexual and reproductive health in Bangladesh a needs assessment. International Planned Parenthood Federation and Family Planning Association of Bangladesh .

Blanc, A., \& Way, A. (1998). Sexual behavior and contraceptive knowledge and use among adolescents in developing countries. Studies in Family Planning, 29, 106-116. http://dx.doi.org/10.2307/172153

Bongaarts, J. (1990). The Measurement of Unwanted Fertility. The Population Council, Working Paper No. 10.

Brackett, J. W. (1978). Family Planning in four Latin American Countries: Knowledge, Use and unmet need. International family planning perspectives and Digest, 4(4), 116-123. http://dx.doi.org/10.2307/2947551

Caroline, H. B., \& Barney, C. (1993). Social Dynamics of Adolescent Fertility in Sub-Saharan Africa. Population dynamics of Sub-Saharan Africa.

Chaudhury, R. H. (1984). The influence of female education, labor force participation, and age at marriage on fertility behavior in Bangladesh. Social Biology, 31(1-2), 59-74.

Chowdhury, A. I., \& Phillips, F. (1989). Predicting Contraceptive Use in Bangladesh: A Logistic Regression Analysis. Journal of Biosocial Science, 2, 161-168.

Chowdhury, R. H. (1977). Education and fertility in Bangladesh. Bangladesh Institute of Development Studies, 5(1), 81-110.

Haide, S. J., Saleh, S. N., Kamal, N., \& Gray, A. (1997). Study of adolescents: Dynamics of perception, attitude, knowledge and use of reproductive health care. Bangladesh: Population Council.

Huq, M. N., \& Cleland, J. (1990). Bangladesh Fertility Survey, 1989. Main Report. Azimpur, Dhaka: National Institute of Population Research and Training.

Kabir, M., Moslehuddin, M., \& Howlader, A. A. (1988). Husband-Wife communication and status of Women as a Determinant of Contraceptive Use in Rural Bangladesh. The Bangladesh Development Studies, 16(1), 86-97.

Kabir, M., Rab, A. K., Ahmed, K. S., \& Saha, U. (2000). Differences between Husbands and Wives in attitudes towards Contraceptive use and Fertility preference. Bangladesh Demographic and Health Survey, $1993-94$.

Khuda, B. (1985). Age at Marriage and Fertility in a Rural Area of Bangladesh. Asian profile, 13(6), $541-553$.

Khuda, et al. (1991). Population In Report of the Task Force on Bangladesh Development Strategies for the 1990s: Policies for Development (Vol. 1). Dhaka: Dhaka University Press.

Ministry of Health and Population Control. (1978). Bangladesh fertility survey 1975-1976; first report. Dacca, Bangladesh: Population Control and Family Planning Division.

Nahar, et al. (1999). Reproductive health needs of adolescents in Bangladesh: A study report. Dhaka, Bangladesh: International Centre for Diarrhoeal Diseases Research, Bangladesh: Center for Health and Population Research.

National Institute of Population Research and Trainging (NIPORT). (2003). Bangladesh Maternal Health Services and Maternal Mortality Survey 2001. Dhaka, Bangladesh: ICDDR,B: Centre for Health and Population Research, Johns Hopkins University, Baltimore, Maryland, USA, and ORC Macro, Calverton, Maryland, USA.

National Institute of Population Research and Training (NIPORT). (2001). Bangladesh Demographic and Health Survey 1999-2000. Dhaka, Bangladesh: Mitra and Associates, Macro International, Calverton, Maryland USA.

National Institute of Population Research and Training (NIPORT). (2009). Bangladesh Demographic and Health Survey-2007. Dhaka, Bangladesh: Mitra and Associates, Dhaka, Bangladesh, Macro International, Calverton, Maryland USA.

Tuladhar, J. M. (1985). Determinants of contraceptive use in Nepal. Journal of Biosocial Science, 17(2), $185-193$. 
http://dx.doi.org/10.1017/S0021932000015637

United Nations Economic Commission for Latin America and the Caribbean (UNECLAC). (1987). A Review of the Fertility Situation in Countries in the Region of the Economic Commission for Latin America and the Caribbean. Fertility Behaviour in the Context of Development: Evidence from the World Fertility Survey, Population Studies, 100, 299-323.

United Nations. (1987). Population policy, Population Bulletin-19/20, 1986. United Nations publication, Sales No. E.87. XIII.2.

World Health Organization (WHO). (1975). Pregnancy and abortion in adolescence: Report of a WHO Meeting. Geneva: WHO Technical Report. Series No. 583.

Xenos, P., \& Kabamala, M. (2002). A comparative history of Age-structure and social transitions among Asian youth. East-West Center Working Paper, Population Series, 110, 26.

Yinger, N., Sherbinin, A. D., Ochoa, L. H., Morris, L., \& Hirsch, J. (1992). Adolescent Sexual Activity and Childbearing in Latin America and the Caribbean: Risks and Consequences. Washington, DC: Population Reference Bureau, International Programs. 